\title{
Family, religion, and depressive symptoms in caregivers of disabled elderly
}

\author{
Maria-Victoria Zunzunegui, François Béland, Alicia Llácer, Ingrid Keller
}

\begin{abstract}
Study objective-To explain the variations in depressive symptomatology among primary caregivers of community dwelling activities of daily living disabled elderly and to evaluate the role of family and religiosity on the mental health consequences of caregiving in Spain.

Design-Cross sectional study.

Setting-City of Leganés in the metropolitan area of Madrid, Spain.

Participants-All caregivers of a representative sample of community dwelling activities of daily living disabled persons, aged 65 and over were approached. The response rate was $85 \%(n=194)$. Depression was assessed by the Center for Epidemiologic Studies Depression (CES-D) Scale.

Main results-Controlling for caregivers' income, education, health status, and caregiving stress, religiosity was associated with more depressive symptoms among children caregivers while for spouses the association was negative. Emotional support was negatively associated with depression, but instrumental support was not significant.

Conclusions-Depressive symptomatology is frequent among Spanish caregivers of disabled elderly. This study concludes that religiosity and family emotional support play an important part in the mental health of Spanish caregivers. The role of religiosity may be different according to kinship tie and needs further investigation.

(F Epidemiol Community Health 1999;53:364-369)
\end{abstract}

Escuela Andaluza de Salud Pública, Granada, Spain M-V Zunzunegui I Keller

GRIS, Faculté de Medecine, Université de Montréal, Canada F Béland

Centro Nacional de Epidemiología, Madrid, Spain

A Llácer

Correspondence to: Maria-Victoria Zunzunegui, Escuela Andaluza de Salud Pública, Apartado 2070, Granada 18080, Spain.

Accepted for publication 18 November 1998
Caring for the disabled elderly is a stressful process, with consequences on the mental health of caregivers. ${ }^{1}$ The stress of caregiving ${ }^{1}$ increase the risk of mental health problems ${ }^{2-4}$ and tends to constrict the social life of the caregiver to a world centred on the cared person. ${ }^{5-7}$ Family conflict, generated by disagreement over the needs of the cared person or the involvement required to satisfy those needs, creates an external strain that adds to the primary stressors. ${ }^{8}$ The concept of self may be modified as a consequence of the outside strains occasioned by caregiving. ${ }^{8}$ More specifically, mastery and self esteem have been shown to diminish as a consequence of the care process. ${ }^{89}$ Some evidence has been provided on the protective effect of emotional support on the mental health of caregivers. ${ }^{10} 11$

Most studies on the effects of caregiving on the carer's mental health have been done in
North America and Great Britain. ${ }^{2}{ }^{4}$ There is a lack of knowledge on the health consequences of caregiving in southern European countries, where family involvement is higher and home care services are less developed than in northern European countries ${ }^{12}$ and North America. Recent research has shown that help received by the Spanish elderly comes, not just mainly, but almost exclusively from their families. ${ }^{13} 14$

According to Pearlin, ${ }^{1}$ caregiving is a process comprising the characteristics and resources of caregivers and the primary and secondary stressors to which they are exposed. Primary stressors are hardships anchored directly in caregiving. Secondary stressors are the diminishment of self concepts and strains in activities outside of caregiving. Guided by Pearlin's conceptual framework, ${ }^{1}$ this work explores the influence of religion and family support upon the risk of depression in a population of Spanish caregivers. According to this model, the risk of depression is determined by the socioeconomic and health characteristics of the caregiver, the primary stressors of caregiving, and the available resources (family, religion, self concepts).

Family structure and culture in Spain are different from those of North America and northern Europe. In Spain, many of those now over 65 , lived during a period when education was inaccessible to the general population, a period when moral obligations were instilled through the observance of Catholic commandments in the family and the church. There is evidence that religious involvement has a protective effect under conditions of stress. ${ }^{15}$ In particular, results on the effect of religion in the health of the elderly show that those who turned to religion in times of stress had a lower risk of psychological distress than those elderly who are not involved in religious activities. ${ }^{16}{ }^{17}$ Religious involvement has been mentioned in qualitative studies ${ }^{18}$ both by spouse and children caregivers as a way to accept the caregiver's role. In a national survey of Spanish caregivers, $90 \%$ of them reported that the main reason for taking care of their disabled family members was because they felt they had a moral obligation to do so. ${ }^{13}$ Moral obligations may differ according to kinship ties, a daughter may feel responsibilities of care to a lesser degree than spouses. We have extended the original Pearlin's model to include religiosity and kinship tie between the caregiver and the cared person.

The objective of this work is to examine variations in depressive symptomatology among primary caregivers of a representative sample of community dwelling activities of daily living 
(ADL)-disabled elderly and to evaluate the role of family and religiosity on the mental health consequences of caregiving in Spain. Our hypotheses are that: (1) the association between objective indicators of caregiving stress and depressive symptoms may be different according to kinship tie; (2) family support to caregivers is associated with lower levels of depression; and (3) religiosity may diminish the effect of caregiving stress on depressive symptomatology.

\section{Methods}

POPULATION AND SAMPLE

Caregivers in this study are primary caregivers of ADL-disabled persons aged 65 years and over. They were identified during the fieldwork for the second wave of the longitudinal study, "Ageing in Leganés"14 during April-June 1995. Data were collected on 1115 people over age 65. Leganés is a city in the Madrid metropolitan area with 171400 inhabitants, $8 \%$ of whose population are aged 65 and over.

\section{IDENTIFICATION OF PRIMARY CAREGIVERS}

Each ADL-dependent elderly was asked to give the name and address of the person who helped the most in the following six personal care activities: bathing, grooming, transferring, using the toilet, walking across a small room, and eating.

In the period between March and June 1996, all caregivers identified in 1995 were located and those who accepted to participate were interviewed during home visits by a trained interviewer using a structured questionnaire. The information gathered during the interview included: sociodemographic and economic characteristics, religiosity, kinship tie, health and functional status, type of care provided, behavioural problems and incontinence of the cared person, emotional and instrumental support, social life, use of public and private health services, depressive symptoms, and psychological resources.

Of the 255 primary caregivers identified as explained above, 229 were eligible (both the disabled elderly and the caregiver were alive and continued to live in Leganés) and 194 were interviewed (overall response rate $=85 \%$ ). The missing interviews were because of absence of the caregiver during five visits $(n=12)$, unwillingness to participate $(n=14)$, or others $(n=9)$.

The sample population consisted of 68 caregivers pertaining to the same generation (66 spouses and 2 sisters) and 126 caregivers belonging to a younger generation. In this second group, 99 were daughters, 6 were sons and 21 were other female relatives (daughters in law, nieces, and granddaughters). The mean age for spouse caregivers was 75.7 years (SD 6.6) and for the younger generation of caregivers the mean was 60.7 years (SD 7.7). Ninety seven per cent of the study population were Catholic. Regarding formal education, $41.2 \%$ had not completed primary education. Some $88.7 \%$ were married and $82.5 \%$ had a monthly family income of more than 70000 pesetas $(150$ pesetas $=1$ US $\$$ ).
MEASUREMENT OF THE VARIABLES

The dependent variable in this study is the presence of depressive symptomatology measured as a score of 16 and over in the CES-D, a cut off point used in most studies. The Spanish version of the CES-D from the Hispanic Health and Nutrition Examination Survey ${ }^{19}$ was used. In the elderly sample of the study "Ageing in Leganés," the Chronbach reliability coefficient was 0.90 , while in this sample of caregivers the coefficient was 0.91 .

SOCIODEMOGRAPHIC VARIABLES

Age was grouped in four categories: <54, 55-64, 65-74 and 75+ years. Income was grouped into two categories: less than 70000 pesetas (=470\$US) and more than 70000 pesetas per month. Subjects were classified into two categories according to level of education: incomplete primary education and complete primary education. Marital status was classified in two categories: married or unmarried.

\section{HEALTH AND FUNCTIONAL STATUS}

The variables considered were the number of chronic conditions, the number of pains and symptoms, functional limitations in the lower and upper extremities, and instrumental activities of daily living (IADL) and ADL disability. When asked if they had ever had any of 13 chronic conditions, caregivers reported an average of 3.9 (SD 2.26) chronic conditions. To assess general symptoms and pains, caregivers were asked if during the past two weeks they had experienced back or low back pain, chest pain, headache, aching legs or swollen ankles, nausea, difficulties in breathing or excessive tiredness. Here the mean number of problems reported was 3.4 (SD 2.34) (maximum $=9$ ). Both variables, chronic conditions and pains/symptoms, were counted, then added up separately for each subject and grouped into four categories each: $0-1,2-34-5$ or $6+$.

Seven questions were included on the function of lower and upper extremities. ${ }^{20}$ Two measurements of disability were obtained from five Activities of Daily Living and five Instrumental Activities of Daily Living. Answers to the items in each of the three scales of functional limitations, ADL and IADL disability were coded as: "no difficulty," "some difficulty," "a lot of difficulty," and "unable." These answers were grouped into three categories for each variable: able (no difficulty), with difficulties (if difficulty in at least one item) and unable (if unable in at least one item).

\section{CAREGIVING STRESS}

The five indicators of objective primary stressors associated to caregiving were (1) amount of help provided for ADL, (2) outdoors-IADL, (3) indoors-IADL, (4) incontinence, and (5) conflictive behaviour. The caregiver was asked if he/she was providing care for each of nine ADL, five indoors-IADL, and five outdoors-IADL. On the average, help was provided in 3.1 ADL (SD 2.8), 3.6 indoors-IADL (SD 1.48) and 3.7 outdoors-IADL (SD 1.53). Incontinence of the cared elderly was reported 
Table 1 Prevalence of depressive symptoms by socioeconomic and health characteristics of the caregiver

\begin{tabular}{|c|c|c|c|c|}
\hline & Number & $\% C E S D \geqslant 16$ & $p$ value & OR $(95 \% C I)$ \\
\hline Sex & & & 0.17 & \\
\hline Men & 35 & 42.9 & & 1.0 \\
\hline Women & 159 & 30.8 & & \\
\hline Age & & & 0.03 & \\
\hline$<54$ & 69 & 26.1 & & 1.0 \\
\hline $55-64$ & 54 & 25.9 & & $1.0(0.4,2.3)$ \\
\hline $65-74$ & 34 & 38.2 & & $1.8(0.7,4.3)$ \\
\hline $75+$ & 37 & 51.4 & & $3.0(1.3,7.0)$ \\
\hline Civil status & & & 0.28 & \\
\hline Married & 172 & 34.3 & & $1.8(0.6,5.0)$ \\
\hline Unmarried & 22 & 22.7 & & 1.0 \\
\hline Family income & & & $<0.001$ & \\
\hline$<70000$ ptas & 34 & 61.8 & & $4.1(1.9,8.7)$ \\
\hline$>70000$ ptas & 160 & 26.9 & & 1.0 \\
\hline Education & & & 0.02 & \\
\hline Incomplete primary & 114 & 39.5 & & $2.1(1.1,4.0)$ \\
\hline Complete primary & 80 & 23.8 & & 1.0 \\
\hline Number of chronic conditions & & & $<0.001$ & \\
\hline $0-1$ & 43 & 11.6 & & 1.0 \\
\hline $2-3$ & 44 & 20.5 & & $2.0(0.6,6.5)$ \\
\hline $4-5$ & 62 & 32.3 & & $3.7(1.3,10.8)$ \\
\hline $6+$ & 45 & 66.7 & & $15.6(5.1,47.7)$ \\
\hline $\begin{array}{l}\text { Number of health problems and } \\
\text { pains }\end{array}$ & & & $<0.001$ & \\
\hline $0-1$ & 60 & 11.7 & & 1.0 \\
\hline $2-3$ & 48 & 20.8 & & $2.0(0.7,5.8)$ \\
\hline $4-5$ & 40 & 45.0 & & $6.3(2.3,17.2)$ \\
\hline $6+$ & 46 & 63.0 & & $13.1(4.9,35.4)$ \\
\hline Physical limitations & & & $<0.001$ & \\
\hline None & 91 & 16.5 & & 1.0 \\
\hline Some & 80 & 46.3 & & $4.0(2.0,8.1)$ \\
\hline Many & 23 & 52.2 & & $5.2(2.0,14.0)$ \\
\hline ADL disability & & & $<0.001$ & \\
\hline No difficulty & 141 & 23.4 & & 1.0 \\
\hline Some difficulty & 35 & 57.1 & & $4.4(2.0,9.5)$ \\
\hline Unable & 18 & 61.1 & & $5.2(1.8,14.4)$ \\
\hline IADL disability & & & $<0.001$ & \\
\hline No difficulty & 149 & 26.2 & & 1.0 \\
\hline Some difficulty & 34 & 50.0 & & $2.6(1.2,5.6)$ \\
\hline Unable & 11 & 72.7 & & $7.4(1.9,29.3)$ \\
\hline
\end{tabular}

CES-D = Center for Epidemiologic Studies Depression Scale.

$\mathrm{p}$ Value from $\chi^{2}$ test for homogeneity of proportions.

by $29.3 \%$ of the caregivers and it was treated as a separate variable because a report on caregivers in Spain cited incontinence as the most bothersome problem for caregivers. ${ }^{18}$ Conflictive behaviour of the cared elderly was measured using the scale proposed by Pearlin (14 behavioural items). For the statistical analysis, the answers were grouped into two categories "any conflictive behaviour" or "none."

KINSHIP TIE

Regarding the relationship with the person cared for, the following groups were identified: caregiver and person cared for are from the same generation (66 spouses, 2 siblings) or the caregiver is from a younger generation (105 children, 21 other female younger family members). From here on, we shall refer to the first group as the spouses and the second group as the children caregivers.

RELIGIOSITY

To measure religious involvement, self reported religiosity was selected over other indicators because of its reported stability over time. ${ }^{21}$ That indicator was then categorised into three groups (very, somewhat, or not at all).

SOCIAL SUPPORT

Emotional support was assessed with nine statements about significant others. ${ }^{1}$ These items evaluated the perceived availability of
KEY POINTS

- Depression is frequent among Spanish family caregivers.

- There are no differences in the associations of caregiving stress with depression between spousal and parental caregivers.

- Family emotional support is associated to lower levels of depression among Spanish caregivers.

- Religion may have a different role for spousal and parental caregivers' well being.

trustworthy relationships. The scale had response categories that ranged from "strongly agree"(1) to "strongly disagree"(5) (Cronbach's alpha=0.91). The higher the score, the lower the support. Lastly, the availability of a secondary caregiver was taken as a measure of instrumental support: $25.8 \%$ of the subjects did not receive help from a secondary caregiver. Only two persons cited formal services as secondary caregivers.

\section{PSYCHOSOCIAL RESOURCES}

Two self concepts were considered: mastery, the control that people feel they are able to exercise over forces that influence their lives; and self esteem, the regard in which you hold yourself. ${ }^{8}$ The mastery and the self esteem scales have high reliability coefficients: Cronbach alphas were 0.82 for both scales. These two scales were used as continuous normal variables in the analysis. For the mastery scale, the higher the score, the higher the internal control of the situation. The scale for self esteem was inverted. Therefore, the higher the score, the lower the self esteem.

\section{STATISTICAL ANALYSIS}

A series of hierarchical logistic regression equations were fitted. Variables were entered into the model according to the causal order hypothesised as explained in the introduction: firstly, caregiver's socioeconomic (model A) and health status indicators (model B) are considered background variables. Secondly, the inclusion of burden of care indicators and their interactions with kinship tie allow testing for the association of burden of care with depression and the modifying effect of kinship tie on this association (model C). Thirdly, the associations of resources with depression are considered: religion and its possible interactions with burden of care and kinship tie (model D), social support (model E), and psychosocial resources (model F). Variables that reached statistical significance at $\mathrm{p}<0.05$ were retained in the model for all subsequent steps. The analysis has been carried out using SPSS 7.0.

\section{Results}

Table 1 shows the bivariate associations of depression with sociodemographic variables, health, and functional status measures. The proportion of men with a CES-D $\geqslant 16$ is higher than in women, although this association is not 
Table 2 Depressive symptoms and primary stressors

\begin{tabular}{|c|c|c|c|c|}
\hline & Number & $\% C E S D \geqslant 16$ & $p$ Value & $O R(95 \% C I)$ \\
\hline \multicolumn{5}{|c|}{ A Prevalence of depressive symptoms by incontinence and conflictive behaviour } \\
\hline Incontinence & & & 0.06 & \\
\hline Yes & 56 & 42.9 & & $1.9(1.0,3.6)$ \\
\hline No & 138 & 29.0 & & 1.0 \\
\hline \multicolumn{3}{|l|}{ Conflictive behaviour } & $<0.001$ & \\
\hline Yes & 145 & 40.7 & & $6.2(2.3,16.4)$ \\
\hline \multirow[t]{2}{*}{ No } & 49 & 10.2 & & \\
\hline & Mean & Standard deviation & $p$ Value & \\
\hline \multicolumn{5}{|c|}{ B Mean number of activities of daily living carried out by caregiver by depressive status } \\
\hline \multicolumn{3}{|c|}{ Number of ADL activities } & 0.02 & \\
\hline $\mathrm{CESD} \geqslant 16$ & 3.89 & 2.92 & & \\
\hline CESD $<16$ & 2.68 & 2.58 & & \\
\hline \multicolumn{2}{|l|}{$\begin{array}{l}\text { Number of IADL outdoor } \\
\text { activities }\end{array}$} & & 0.25 & \\
\hline $\mathrm{CESD} \geqslant 16$ & 3.51 & 1.70 & & \\
\hline CESD $<16$ & 3.78 & 1.43 & & \\
\hline \multicolumn{2}{|l|}{$\begin{array}{l}\text { Number of IADL indoor } \\
\text { activities }\end{array}$} & & 0.967 & \\
\hline $\mathrm{CESD} \geqslant 16$ & 3.62 & 1.54 & & \\
\hline CESD $<16$ & 3.61 & 1.45 & & \\
\hline
\end{tabular}

CES-D = Center for Epidemiologic Studies Depression Scale.

$\mathrm{p}$ Value from $t$ test for means comparisons.

Table 3 Prevalence of depressive symptoms by kinship ties and religiosity

\begin{tabular}{lllll}
\hline & Number & $\%$ CESD $\geqslant 16$ & $p$ Value & OR $(95 \%$ CI) \\
\hline Kinship tie & 68 & 45.6 & 0.02 & \\
$\quad$ Spouses & 126 & 26.6 & & $2.4(1.2,4.4)$ \\
$\quad$ Children & & & 0.28 & 1.0 \\
Religiosity & 92 & 29.3 & & 1.0 \\
$\quad$ Not at all & 64 & 40.6 & & $1.6(0.8,3.1)$ \\
Somewhat & 38 & 28.9 & & $0.8(0.3,1.9)$ \\
$\quad$ Very & & &
\end{tabular}

CES-D = Center for Epidemiologic Studies Depression Scale.

$\mathrm{p}$ Value from $\chi^{2}$ test for homogeneity of proportions.

statistically significant. Increasing risk of depression is observed with increasing age $(\mathrm{p}=0.03)$. Among the sociodemographic variables, income shows the strongest and highest significant effect $(\mathrm{p}<0.001)$, with higher income being associated with lower depression. Lower education was associated with higher depression (table 1).

All variables measuring health and functional status are strongly related to depression (table 1). The more chronic conditions or pains/symptoms a subject reports, the more probable they will have depressive symptoms. Subjects with fewer functional limitations show lower prevalence of depression. More than half of the caregivers who are unable to perform ADLs and IADLs have a score of CES-D $\geqslant 16$, compared with one quarter of those who were completely able.

Table 4 Means of self esteem, mastery, and emotional support by presence of depressive symptoms

\begin{tabular}{llll}
\hline & Mean & Standard deviation & p Value \\
\hline Self esteem & & & $<0.001$ \\
CESD $\geqslant 16$ & 17.41 & 4.22 & \\
CESD $<16$ & 12.11 & 3.97 & $<0.001$ \\
Mastery $\dagger$ & & & \\
CESD $\geqslant 16$ & 12.48 & 3.75 & $<0.001$ \\
CESD $<16$ & 17.80 & 3.87 & \\
Emotional & & & \\
$\quad$ support & & 7.6 & \\
CESD $\geqslant 16$ & 19.7 & 7.6 & \\
CESD $<16$ & 14.2 & 5.5 & \\
\hline
\end{tabular}

* The higher the score, the lower the self esteem and the emotional support.

† The higher the score, the higher the mastery.

CES-D = Center for Epidemiologic Studies Depression Scale. $\mathrm{p}$ Value from $t$ test for means comparisons.
Among the objective stressors associated to caregiving, incontinence, conflictive behaviour and ADL dependency are associated to high depression scores among the caregivers (table $2 \mathrm{~A}$ and $\mathrm{B})$. However, the number of outdoors or indoors IADL for which the caregiver provides assistance is not associated to high depressive symptomatology (table 2B).

Caregivers pertaining to the same generation as care recipients show a higher CES-D score when compared with caregivers belonging to the following generation. The relation between religiosity and depression is not significant in the bivariate analysis (table 3 ). The association between emotional support and the caregiver's depressive symptomatology is very significant. Self esteem and mastery are strongly related to depression in the hypothesised direction (table 4).

Table 5 shows the results of the hierarchical regressions. Model A includes only the socioeconomic characteristic. Prevalence of depression was higher in those with low income. Once income was taken into account, neither age nor sex of the caregiver was associated to depression. In model B, those with chronic diseases and those with general pains and symptoms had higher prevalence of depression.

Model C includes primary stressors and kinship tie. Primary stressors entered into the model were number of ADL, conflictive behaviour, and number of outdoors IADL that were done for disabled elderly. Incontinence, the number of indoor IADL that were done for the elderly and kinship ties were not associated to depression. None of the interactions of primary stressors with kinship tie were significant. Model D includes religiosity and the interactions of religiosity with primary stressors and kinship tie; thus, the main effect of kinship ties had to be added to the model at this step. The interaction of religiosity with kinship tie attained statistical significance. As expected, for spouse caregivers high religiosity is associated with low levels of depression. However, for children caregivers, the opposite is true: those with high levels of religiosity show higher prevalence of depression. Model E includes emotional and instrumental support. Emotional support is negatively and significantly associated to depression, while existence of a secondary caregiver is not associated with lower or higher levels of depression. In the final model (Model F), the associations of mastery and self esteem with depression are significant as expected. Income and health status indicators lost statistical significance when mastery and self esteem were entered into the model. The 95\% confidence intervals for the odds ratios of the interactions between religiosity and kinship ties are attributable to overestimation of standard errors produced by collinearity between the main effects and the multiplicative interaction terms. Although these confidence intervals are inaccurate, hypothesis testing of the interaction tests by comparison of likelihood functions gives a $\mathrm{p}$ value $<0.001$. 
Table 5 Hierarchical logistic regression estimation of odds ratios relating depressive symptomatology in caregivers to risk factors for depression

\begin{tabular}{|c|c|c|c|c|c|c|c|c|c|c|c|c|}
\hline & \multicolumn{2}{|c|}{$\begin{array}{l}\text { Model } A \\
\text { socioeconomic } \\
\text { variables }\end{array}$} & \multicolumn{2}{|c|}{$\begin{array}{l}\text { Model B } \\
\text { health status }\end{array}$} & \multicolumn{2}{|c|}{$\begin{array}{l}\text { Model } C \\
\text { burden of care }\end{array}$} & \multicolumn{2}{|c|}{$\begin{array}{l}\text { Model D } \\
\text { religion }\end{array}$} & \multicolumn{2}{|c|}{$\begin{array}{l}\text { Model E } \\
\text { family support }\end{array}$} & \multicolumn{2}{|c|}{$\begin{array}{l}\text { Model F } \\
\text { psychological } \\
\text { resources }\end{array}$} \\
\hline & $O R$ & $95 \% C I$ & $O R$ & $95 \% C I$ & $O R$ & $95 \% C I$ & $O R$ & $95 \% C I$ & $O R$ & $95 \% C I$ & $O R$ & $95 \% C I$ \\
\hline \multicolumn{13}{|l|}{ Socioeconomic characteristics } \\
\hline Income (low $v$ high) & 4.3 & $(9.4,2.0)$ & 3.3 & $(8.1,1.3)$ & 3.1 & $(8.3,1.1)$ & 3.6 & $(12.7,1.0)$ & 3.6 & $(14.4,0.9)$ & 3.6 & $(20.4,0.6)$ \\
\hline \multicolumn{13}{|l|}{ Health status variables } \\
\hline \multicolumn{13}{|l|}{ Number of chronic conditions } \\
\hline $2-3 v 0-1$ & & & 0.8 & $(3.1,0.2)$ & 0.8 & $(3.1,0.2)$ & 0.9 & $(3.8,0.2)$ & 0.8 & $(3.5,0.2)$ & 2.3 & $(18.3,0.3)$ \\
\hline $4-5 v 0-1$ & & & 1.2 & $(4.1,0.3)$ & 1.0 & $(3.8,0.3)$ & 1.1 & $(4.4,0.3)$ & 1.0 & $(4.3,0.2)$ & 2.5 & $(18.2,0.3)$ \\
\hline $6+v 0-1$ & & & 3.7 & $(13.6,1.0)$ & 4.1 & $(16.6,1.0)$ & 4.8 & $(21.5,1.1)$ & 4.1 & $(20.2,0.8)$ & 9.5 & $(75.7,1.1)$ \\
\hline \multicolumn{13}{|l|}{ Number of pains and symptoms } \\
\hline $2-3 v 0-1$ & & & 1.9 & $(6.2,0.6)$ & 1.7 & $(0.5,5.9)$ & 1.4 & $(5.2,0.4)$ & 1.2 & $(5.0,0.3)$ & 0.5 & $(3.5,0.1)$ \\
\hline $4-5 v 0-1$ & & & 5.8 & $(18.5,1.8)$ & 4.7 & $(16.7,0.5)$ & 3.9 & $(16.0,0.9)$ & 4.1 & $(19.4,0.9)$ & 1.9 & $(13.2,0.5)$ \\
\hline $6+v 0-1$ & & & 6.2 & $(22.5,1.7)$ & 5.7 & $(21.2,1.3)$ & 5.3 & $(21.4,1.3)$ & 6.7 & $(31.8,1.4)$ & 4.3 & $(27.2,0.7)$ \\
\hline \multicolumn{13}{|l|}{ Primary stressors } \\
\hline Conflictive behavious (yes $v$ no) & & & & & 4.0 & $(14.8,1.1)$ & 5.0 & $(19.7,1.3)$ & 6.9 & $(31.1,1.5)$ & 2.6 & $(18.5,0.3)$ \\
\hline Number of ADL & & & & & 1.3 & $(1.5,1.1)$ & 1.3 & $(1.6,1.1)$ & 1.2 & $(1.5,1.0)$ & 1.2 & $(1.6,0.9)$ \\
\hline Number of outdoor IADL & & & & & 0.6 & $(0.9,0.4)$ & 0.6 & $(0.9,0.4)$ & 0.5 & $(0.8,0.4)$ & 0.6 & $(0.9,0.3)$ \\
\hline \multicolumn{13}{|l|}{ Interactions of kinship tie by religiosity } \\
\hline \multicolumn{13}{|l|}{ Spouses } \\
\hline Spouses non-religious & & & & & & & 11.6 & $(77,1.7)$ & 19.1 & $(134,1.8)$ & 24.1 & $(671,1.7)$ \\
\hline Spouses somewhat religious & & & & & & & 5.8 & $(42,0.8)$ & 10.9 & $(90,1.0)$ & 11.8 & $(241,0.6)$ \\
\hline Spouses very religious & & & & & & & 1.0 & & 1.0 & & 1.0 & \\
\hline \multicolumn{13}{|l|}{ Children } \\
\hline Children non-religious & & & & & & & 1.9 & $(2.7,0.4)$ & 2.1 & $(45,0.2)$ & 3.2 & $(132,1.0)$ \\
\hline Children somewhat religious & & & & & & & 7.7 & $(58.0,1.0)$ & 11.9 & $(226,0.5)$ & 26.3 & $(478,1.4)$ \\
\hline Children very religious & & & & & & & 5.7 & $(40.8,0.8)$ & 12.8 & $(132,1.0)$ & 64.7 & $(2724,0.4)$ \\
\hline $\begin{array}{l}\text { Low emotional support }((-1 S D)=6 \text { points } \\
\text { in the scale }))\end{array}$ & & & & & & & & & 2.0 & $(3.3,1.3)$ & 1.5 & $(2.4,1.0)$ \\
\hline Low self esteem $\dagger((+1 \mathrm{SD})=4.7$ points $)$ & & & & & & & & & & & 7.4 & $(3.5,1.7)$ \\
\hline High mastery $\dagger((-1 \mathrm{SD})=4.7$ points $))$ & & & & & & & & & & & 0.3 & $(0.8,0.1)$ \\
\hline
\end{tabular}

^ Because of colinearity between main effects of religiosity and kinship ties and their interaction terms, standard errors of coefficients are overestimated and $95 \%$ confidence intervals for odds ratios are inaccurate. Inclusion of interactions terms improved the likelihood of models D, E, and F, indicating statistical significance of these interactions. $†$ Estimates of odds ratios associated to a change of one standard deviation in risk factor.

\section{Discussion}

Testing of the hypotheses formulated in the introduction produce the following results: (1) associations between caregiving stressors and depressive symptomatology of the caregiver does not vary by kinship tie; (2) family support is associated to lower levels of depression, and (3) religiosity is protective for depression among spouse caregivers while among children caregivers, high religiosity is associated with more depressive symptoms.

Some general information on the social context of caregiving in Spain is warranted before discussing the significance of these results. Institutionalisation of the elderly occurs rarely. Only $2.8 \%$ of people over 65 live in institution, ${ }^{18}$ and most of these homes for the elderly $(78 \%)$ are not nursing homes, nor are they equipped for disabled people. Only a minority of Spanish families can rely on private institutional arrangements, which can cost an average of 130000 pesetas/month: more than double the minimum wage salary. Therefore, most disabled elderly live in the community with their family. ${ }^{13}$ Regarding living arrangements, around $18 \%$ of those above 65 live alone and the proportion of elderly living alone decreases after the age of $80 .{ }^{13}$ Formal community services are very scarce. Less than $1 \%$ of the elderly receive any kind of formal care. $^{13}$

For these reasons, community care provided to elderly comes almost exclusively from the immediate family; only two of the 194 caregivers in our sample received help from formal services. In addition, the social life of the Spanish elderly is centred on the family. ${ }^{14}$ Under these circumstances, the family assumes practically all the responsibility for care, and within the family, more specifically, the women. ${ }^{14}$ Thus, family support already identified as mediators in the stress process associated to caregiving, ${ }^{81011}$ plays a central part in elderly care in Spain. ${ }^{22}$

The caregivers in our study have a high prevalence of known risk factors for depression, which may modify the association of caregiving with depression. Income, comorbidity, pains and symptoms remain significant when caregiving indicators were entered in model C. These results coincide with previous research on depressive symptomatology of the elderly population of Leganés. However, self esteem and high mastery seem to play an intervening part between income and health status associations with depression. Having a good health condition and a good economic situation may be particularly important for caregivers, because their self esteem and sense of mastery increase with both. ${ }^{8}$

Interactions of caregiving stressors and kinship ties are not statistically significant, thus our second hypothesis had to be rejected. However, some stressors are significantly related to depression. Incontinence and conflictive behaviour have been mentioned repeatedly as the most unbearable problems in a Spanish national study of caregivers, ${ }^{18}$ and in international studies. ${ }^{23}{ }^{24}$ Both were statistical significant in the bivariate analysis, but only conflictive behaviour was significant in the multivariate analysis. Again, low self esteem and high mastery reduced below the level of statistical significance the coefficient for conflictive behaviour. The number of ADL activities in which caregivers lend assistance entered into the model but lost significance when family support was entered. In this study we have 
distinguished between indoors and outdoors IADL activities. The protective effect of providing help in outdoors activities remains significant until the final model. Going outdoors to do errands for the cared person implies being in touch with stores and agencies in the community, which provide goods and services for the cared persons. In Spain, this exchange provides caregivers with opportunities to talk about the cared person and the caregiving process.

Evidence of the effect of family support on depression of the caregiver is scarce. ${ }^{25}$ Social support may be mobilised either as a consequence of a crisis situation or it may have existed before the onset of the elderly person's disability, within a context of reciprocity between spouses and generations. Some North American and British studies do not find evidence for the beneficial effects of social support..$^{102}$ In our study, however, these beneficial effects are significant. Those with lower levels of emotional support have higher prevalence of depression. However, mastery and self esteem reduced below the level of statistical significance the coefficient for emotional support. The relations between mastery, self esteem, and depression are expected and confirm results from previous studies. ${ }^{1}{ }^{10}$

Research on religiosity and stress has shown that high levels of self rated religiosity are associated with low levels of depression. ${ }^{15}{ }^{16}$ In our study, the association of religiosity with depression varies according to kinship tie. It seems that religiosity plays a different part in the stress process for Spanish caregivers belonging to different generations. It could be suggested that for the very elderly, religiosity is a resource while for the younger generation it is a response to stressful situations associated to caregiving. An alternative explanation could be that the notion of religiosity for older (and less educated) women in Spain is different from that of relatively younger, better informed, more challenging caregivers. At this stage of our research, with cross sectional data, no satisfactory explanation is available for this finding.

One of the strengths of our study is the representative nature of our sample. All caregivers in a random sample of disabled elderly were identified and $85 \%$ were included. Among its limitations should be mentioned the small sample size, as it weakens the ability to detect significant associations in the multivariate analysis, and the cross sectional nature of the data, which raises questions over the directionality of some of the relations tested.

The conclusion of our study is that religiosity and family emotional support play an important part in the mental health of Spanish caregivers. More specifically, the role of religiosity in the stress process associated to caregiving seems to be different according to kinship tie and the consequences of the stress associated to the care process are mediated by family relationships, in the absence of formal sources of care.

The authors would like to thank the contributions of an anonymous reviewer.

Funding: this work has been financed by the Fondo de Investigaciones Sanitarias: Proyecto 95/549.

Conflicts of interest: none.

1 Pearlin LI, Mullan JT, Semple SJ, et al. Caregiving in the stress process: an overview of the concepts and their measure. Gerontologist 1990;30:583-91.

2 Baumgarten $M$. The health of persons giving care to the demented elderly: A critical review of the literature. $f$ Clin Epidemiol 1989;42:1137-48.

3 Livingston G, Manela M, Katona C. Depression and other psychiatric morbidity in carers of elderly people living at home. BMF 1996;312:153-6.

4 Schulz R, Visintainer P, Williamson GM. Psychiatric and physical morbidity effects of caregiving. F Gerontol 1990;45: $181-91$.

5 George L, Gwyhter LP. Caregiver Well-being: A multidimensional examination of family caregivers of demented adults. Gerontologist 1986;26:253-9.

6 Moritz DJ, Kasl SV, Berkman LF. The health impact of living with a cognitively impaired elderly spouse: depressive symptoms and social functioning. F Gerontol 1989;44:S1727.

7 Chenoweth B, Spencer B. Dementia: The experience of family caregivers. Gerontologist 1990;26:267-72.

8 Aneshensel CS, Pearlin LI, Mullan JT, et al, eds. Profiles in caregiving. New York: Academic Press, 1995.

9 Miller B, Campbell RT, Farran CJ, et al. Race, control, mastery and caregivers distress. F Gerontol 1995;50B:S374-82.

0 Baillie V, Norbeck JS, Barnes LEA. Stress, social support, and psychological distress of family caregivers of the elderly. Nurs Res 1988;37:217-22.

11 Scott JP, Roberto KA, Hutton JT. Families of Alzheimer's victims. Family support to the caregivers. 7 Am Geriatr Soc 1986;34:348-54.

12 Jamieson A, eds. Home care for older people in Europe: a comparison of policies and practice. Oxford: Oxford University Press, 1991

13 INSERSO. Cuidados en la vejez. El apoyo informal. Madrid: Ministerio de Asuntos Sociales, 1996.

14 Béland F, Zunzunegui MV. The elderly in Spain: The dominance of family and the wherewithal of the State. In: Litwin $\mathrm{H}$, eds. Social networks of older people. London: Praeger, 1996.

15 Ellison CG. Religious involvement and subjective wellbeing. F Health Soc Behav 1991;32:80-99.

6 Idler EL, Kasl SV. Religion, disability, depression and the timing of death. Am $\mathcal{F}$ Soc 1992;97:1052-79.

17 Moen P, Robison J, Dempster-McClain D. Caregiving and women's well-being: A life course approach. 7 Health Soc Behav 1995;36:259-73.

18 INSERSO. Las personas mayores en España. Perfiles. Reciprocidad familiar. Madrid: Ministerio de Asuntos Sociales, 1995.

19 Moscicki EK, Locke B, Rae DS. Depressive Symptoms among Mexicans: the Hispanic Health and Nutrition Examination Survey. Am f Epidemiol 1989;130:348-60.

20 Nagi SZ. An epidemiology of disabled among adults in the United States. Milbank O 1976;54:439-68.

21 Markides KS, Levin JS, Ray LA. Religion, aging, and life satisfaction: an eight year, three wave longitudinal study. Gerontologist 1987;27:660-5.

22 Bazo MT. La familia como elemento fundamental en la salud y bienestar de las personas ancianas. Rev Esp Geriatr Gerontol 1991;2:47-52.

23 Gilleard CJ, Belford H, Gilleard E, et al. Emotional distress amongst the supporters of the elderly mentally infirm. $B r \mathcal{F}$ Psychiatr 1984;145:172-7.

24 Baumgarten $\mathrm{M}$, Battista $\mathrm{RN}$, Infante-Rivard $\mathrm{C}$, et al. The psychological and physical health of family members caring for an elderly person with dementia. $\mathcal{F}$ Clin Epidemiol 1992; 45:61-70.

25 Cantor MH. Strain among caregivers: A study of experience in the United States. Gerontologist 1983;23:597-604. 